\title{
Spinal Interbody Fusion with Unilateral Pedicle Screw Fixation
}

\author{
Ehab Alshal* \\ Orthopedic Department, Faculty of Medicine, AL-Azhar University, Egypt
}

Submission: August 23, 2019; Published: September 09, 2019

*Corresponding author: Ehab Alshal, Orthopedic Department, Faculty of Medicine, AL-Azhar University Assiut City, postal code: 71524 - Assiut, Egypt

\begin{abstract}
The success of lumbar spine fusion depends on good patient selection. Bilateral pedicle instrumentation whit transforaminal interbody fusion, now popular, improves fusion rates, and eliminates the necessity for postoperative braces, also allows early mobilization. However, the stress shielding caused by rigid internal fixation is thought to lead to osteopenia and degeneration of adjacent segments. Theatre times, intra operative complications and costs are increased when pedicle screw fixation is added. The present study retrospectively collected the clinical and radiological data of 21 patients with degenerative lumbar disease managed by transforaminal interbody fusion with unilateral pedicle screw fixation. The fusion rate was $97 \%$ on radiographic analysis and was $96 \%$ on CT scan analysis. A loosening of the screw was reported, without pain. No infections were reported. Transforaminal interbody fusion with unilateral pedicle screw fixation technique has been shown to be effective and safe for patients with lumbar degenerative disease.
\end{abstract}

Keywords: Spinal fusion; Pedicle screw; Degenerative spine; Transforaminal interbody fusion

Abbreviations: CT: Computed Tomography Scan, TLIF: Transforaminal Lumbar Interbody Fusion; ODI: Oswestry Disability Index; VAS: Visual Analogue Score

\section{Introduction}

Transforaminal lumbar interbody fusion (TLIF) was originally described by Harms and Rolinger in 1982 [1]. It has turn out to be one of the ordinary standard techniques for the decompression of the ipsilateral foramen and an appropriate interbody fusion. This procedure is frequently accompanied by the placement of bilateral transpedicular screws in the corresponding segment; this results in immediate rigid segment stabilization that will last while fusion takes places [2,3]. Some authors have proven that excessive stiffness of such a construct can jeopardize the fusion process due to graft resorption that is in hand due to the lack of stress against end plates [4-6].

Scientific evidence in the literature has established that unilateral transpedicular screw fixation, right after fusion, produces radiological results comparable with bilateral fixation: this is done at a lower cost because less amount of implants is used [7-12]. Minimally invasive transforaminal lumbar interbody fusion was originally described by Foley [13]. Which is why the absolute requirement for contralateral pedicle fixation to minimally invasive transforaminal lumbar interbody fusion is, therefore, controversial. Unilateral pedicle screw fixation as a complement to a Minimally invasive transforaminal lumbar interbody fusion has been described since 2006 [14]. Theoretical advantages of this unilateral paramedian posterior approach include a decrease of blood loss, faster surgery procedure, reduced radiation dose, and of course the preservation of the contralateral posterior articular process. It also has similar radiographic fusion rates than open TLIF and a predisposition to yield better clinical results in the immediate postoperative period $[7,8,11,14,15]$. The present study evaluated the clinical effectiveness of unilateral pedicle screw fixation plus transforaminal lumbar interbody fusion in patients with degenerative lumbar disease. The main outcome measure was obtained with Oswestry Disability Index (ODI) and VAS lumbar and VAS Lega pain scores.

\section{Material and Methods}

From January 2015 to December 2018, the clinical and radiological data of patients with degenerative lumbar disease managed by a one-level unilateral pedicle screw fixation plus transforaminal lumbar interbody fusion in our university hospitals were collected. Each patient signed a consent form. A retrospective case-series study was performed in 21 patients with degenerative lumbar disease. The inclusion criteria were patients older than 18 years and treated by a one-level lumbar arthrodesis for lumbar degenerative diseases (patients 


\section{Orthopedics and Rheumatology Open Access Journal (OROAJ)}

with low-grade spondylolithesis, recurrent disc herniation, extraforaminal disc herniation, and lumbar stenosis with unilateral radiculopathy.

Patients with major central stenosis or bilateral radiculopathy, with previous spine surgery with instrumentation, tumors, bilateral radicular pain, obese (BMI> 30), osteoporosis were excluded from the study. Of note, patients with unilateral symptomatic radiculopathy but with evidence of radiographic bilateral foraminal stenosis were included in the study and only

Table 1: patient's demographics.

\begin{tabular}{|c|c|}
\hline Item & Patients \\
\hline Gender & \\
\hline Male & \\
\hline Female & \\
\hline 15 & Median 51,5 y \\
\hline 6 & 28 \\
\hline Age & 12 \\
\hline BMD & 7 \\
\hline Indication & 1 \\
\hline Low-grade spondylolithesis & 1 \\
\hline Discopathy/foraminal stenosis & 4 \\
\hline Extra-foraminal disc herniation & 8 \\
\hline Disc herniation recurrence & 9 \\
\hline Level of arthrodesis & \\
\hline L3/L4 & \\
\hline L4/L5 & \\
\hline L5/S1 & \\
\hline
\end{tabular}

\section{Surgical Technique}

With the patient in prone position under general anesthesia, use of intensified fluoroscopy images with C-arm, surgical approachwas executed on the most symptomatic side. Incision of approx. $3 \mathrm{~cm}$ was performed, using micro-discectomy separators. It is started by placing transpedicular screws of the affected segment and a TLIF separator is used, subsequently a the symptomatic side was directly decompressed. The median age of the patients was 51.1 [29-60] years old. The sample by sex was 15 male patients and 6 female patients. The average body mass index was 28 . The most frequent place of radiculopathy was left. Segment most frequently operated was L4 / L5 (85\%), L5 / S1 (12\%), L3 / L4 (3\%). The main surgical indications were, 14 patients presented low-grade spondylolithesis, with unilateral radiculopathy and 7 patients with Discopathy/ foraminal stenosis. Patient's demographics are listed in Table 1. lamina and articular facet osteotomy and medial facetectomy was completed. The Kambi's triangle is located, the medial and lateral root is retracted, preparation was performed, and bone graft was delivered in the lumbar intersomatic space. A rectangular bulletnose cage was implanted. To conclude, unilateral transpedicular screws were placed on the rod. Figure 1.

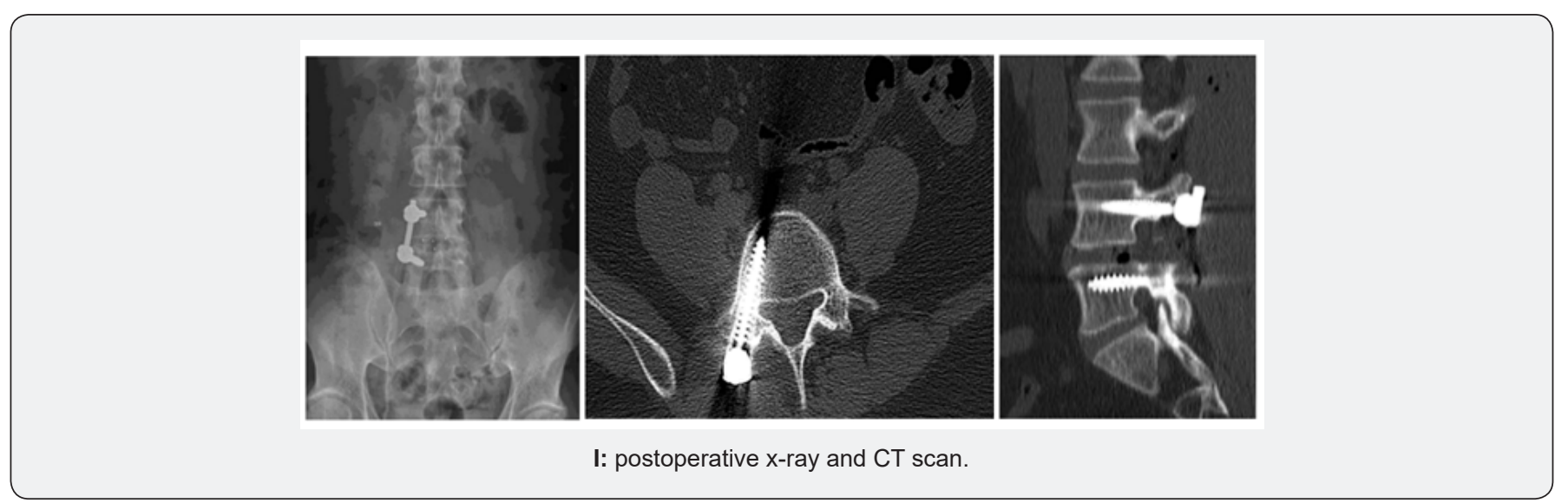




\section{Outcomes}

Clinical outcomes were evaluated pre- and postoperative using the ODI, visual analogue scale (VAS) for leg and back pain, patients must complete a minimum of 2 years of follow-up. Interbody fusion was analyzed on radiography and on a CT scan.

\section{Statistical Analysis}

Recorded data were analyzed using the statistical package for social sciences, version 20.0 (SPSS Inc., Chicago, Illinois, USA). Quantitative data were expressed as mean \pm standard deviation (SD). Qualitative data were expressed as frequency and percentage.

\section{Results}

ODI and VAS were significantly enhanced $(\mathrm{p}<0.05)$ at the end of the follow-up. The mean follow-up was 38 months (range 25-42). There was positive progress from the first 3 months, which was increasing in the subsequent months (Table 2). VAS leg pain improved in all patients. As well as low back pain was improved $(\mathrm{p}<0.01)$. The average hospital time was 3 days, no trans-operative complications, infections or dural tear were reported. All patients at the next day started walking and immediately physical therapy and rehabilitation. Drainage was routinely placed. No patient needed transfusion. At the 3-year follow-up the fusion rate was $95 \%$ on radiographic analysis and was $93 \%$ on CT scan analysis. A loosening of the screw was reported, without pain in one patient treated with rest and physical therapy, with good evolution. No infections were reported. There was a considerable decrease in the use of analgesics in the first 3 months.

Table 2: Results.

\begin{tabular}{|c|c|c|c|}
\hline Item & ODI & VAS & VAS-Leg Pain \\
\hline Pre-operative & 52 & 6.4 & 7.6 \\
\hline 6 months & 23.5 & 3.8 & 1.7 \\
\hline 12 months & 18.7 & 3.8 & 1.1 \\
\hline 24 months & 18.4 & 2.1 & 1 \\
\hline 36 months & 15.1 & 1.9 & 1 \\
\hline Paired test & $\mathrm{P}<0.05$ & $\mathrm{P}<0.05$ & $\mathrm{P}<0.05$ \\
\hline
\end{tabular}

\section{Discussion}

TLIF is described to be a regular surgical alternative for patients with isthmic spondylolithesis and axial pain. Screw fixation goes along with this procedure to deliver better stability. Bilateral screw fixation was first introduced but further research has revealed that unilateral screw fixation represents a good choice for preserving stability of the spine $[14,16,17]$. In spinal fusion surgery, the need for unilateral or bilateral instrumentation is a controversial matter. Biomechanical studies had demonstrated that unilateral fixation after TLIF delivered less rotational stability and stiffness than bilateral pedicle screw fixation $[6,7,17]$. Nevertheless, wide-ranging destruction of tissue structures, which exacerbated considerably the unsteadiness of the spine, was used in these in vitro biomechanical studies. In addition, the maintenance of lumbar stability simply relied on unilateral pedicle screw fixation without any support device. At present, a general consensus was that unilateral instrumentation should be confined to a single-level fusion and not be extended to multilevel fusion because of its inadequate fixation strength.

Kabins et al. [8] described similar clinical and radiographic fusion results among unilateral instrumentation in compare to the present study. Suk et al. [9] designed a prospective study with 87 patients to associate bilateral with unilateral pedicle screw fixation in one or two fused segments, the final conclusion was that unilateral is as effective as bilateral screw fixation in all items appraised: blood loss, operating time, length of hospital stay, clinical outcomes, complication rates and medical expenses. Recently, Xue et al. [12] compared clinical and radiographic outcomes of patients fixed with unilateral pedicle and bilateral concluding that TLIF with unilateral transpedicular screw fixation is an advantageous treatment choice with better results in terms of operative time, blood loss, and hospital stay for single level disease. It is clear that in in vitro models, the rigidity obtained by a bilateral fixation is superior to unilateral. On the other hand, it has been demonstrated that the absence of certain degree of movement can yield to a fusion failure. At the 2-year follow-up, our interbody fusion rate measured with CT (93\%) results very similar to those reported by Kabins et al. (92.3\%) or in Xiao's meta-analysis of 270 cases (92.2\%) [17]. In patients who still did not see a complete fusion, they were asymptomatic, so they did not require a revision surgery.

\section{Conclusion}

This study demonstrates the benefits of minimally invasive one level transforaminal interbody fusion with unilateral pedicle screw fixation in the management of our patients with stable lumbar disease. The results have proven a low rate of perioperative morbidity which is associated with an accelerated worthwhile recovery in the literature. With comparable positive clinical and radiological 2-year outcomes, transforaminal interbody fusion with unilateral pedicle screw fixation may be a valuable surgical alternative to bi-pedicular screw fixation technique in the management of stable lumbar degenerative 
diseases. Additional revisions will be required to endorse these results.

\section{Conflict of Interest}

The author declared that no conflict of interest exists.

\section{References}

1. Harms J, Rolinger H ( 1982) A one-stager procedure in operative treatment of spondylolistheses: dorsal traction-reposition and anterior fusion (author's transl). Z Orthop Ihre Grenzgeb 120(3): 343-347.

2. Xiao YX, Chen QX, Li FC ( 2009) Unilateral transforaminal lumbar interbody fusion: a review of the technique, indications and graft materials. J Int Med Res 37(3): 908-917.

3. Harris BM, Hilibrand AS, Savas PE, Pellegrino A, Vaccaro AR, et al (2004) Transforaminal lumbar interbody fusion: the effect of various instrumentation techniques on the flexibility of the lumbar spine. Spine (Phila Pa 1976) 29(4): E65-E70.

4. Potter BK, Freedman BA, Verwiebe EG, Hall JM, Polly DW Jr, et al. (2005) Transforaminal lumbar interbody fusion: clinical and radiographic results and complications in 100 consecutive patients. J Spinal Disord Tech 18(4): 337-346.

5. McAfee PC, Farey ID, Sutterlin CE, Gurr KR, Warden KE, et al. ( 1991). The effect of spinal implant rigidity on vertebral bone density. A canine model. Spine (Phila Pa 1976) 16(6 Suppl): S190-197.

6. McAfee PC, Farey ID, Sutterlin CE, Gurr KR, Warden KE, et al. (1989). Volvo Award in basic science. Device-related osteoporosis with spinal instrumentation. Spin (Phila Pa 1976) 14(9): 919-926.

7. Goel VK, Lim TH, Gwon J, Chen JY, Winterbottom JM, et al. ( 1991) Effects of rigidity of an internal fixation device. A comprehensive biomechanical investigation. Spine (Phila Pa 1976) 16(3 Suppl): S155161.

8. Kabins MB, Weinstein JN, Spratt KF, Found EM, Goel VK, et al. (1992) Isolated L4- L5 fusions using the variable screw placement system: unilateral versus bilateral. J Spinal Disord 5(1): 39-49.
9. Suk KS, Lee HM, Kim NH, Ha JW (2000) Unilateral versus bilateral pedicle screw fixation in lumbar spinal fusion. Spine (Phila Pa 1976) 25(14): 1843-1847.

10. Beringer WF, Mobasser JP (2006) Unilateral pedicle screw instrumentation for minimally invasive transforaminal lumbar interbody fusion. Neurosurg Focus 20: E4.

11. Deutsch H, Musacchio MJ Jr ( 2006) Minimally invasive transforaminal lumbar interbody fusion with unilateral pedicle screw fixation. Neurosurg Focus 20(3): E10.

12. Xue H, Tu Y, Cai M ( 2012) Comparison of unilateral versus bilateral instrumented transforaminal lumbar interbody fusion in degenerative lumbar diseases. Spine J 12(3): 209-215.

13. Foley KT, Holly LT, Schwender JD (2003) Minimally invasive lumbar fusion. Spine 28(15 Suppl): S26-S35.

14. Tuttle J, Shakir A, Choudhri HF (2006) Paramedian approach for transforaminal lumbar interbody fusion with unilateral pedicle screw fixation. Technical note and preliminary report on 47 cases. Neurosurg Focus 20(3): E5.

15. Cao Y, Chen Z, Jiang C, , Wan S, Jiang X, et al. (2015) The combined use of unilateral pedicle screw and contralateral facet joint screw fixation in transforaminal lumbar interbody fusion. Eur Spine J 24(11): 26072613.

16. Huang P, Wang Y, Xu J, Xiao B, Liu J, et al. ( 2017) Minimally invasive unilateral pedicle screws and a translaminar facet screw fixation and interbody fusion for treatment of single-segment lower lumbar vertebral disease: surgical technique and preliminary clinical results. J Orthop Surg Res 12(1): 117.

17. Xiao SW, Jiang H, Yang LJ, Xiao ZM (2015) Comparison of unilateral versus bilateral pedicle screw fixation with cage fusión in degenerative lumbar diseases: a meta-analysis. Eur Spine J 24(4): 764-774.

\section{Your next submission with Juniper Publishers} will reach you the below assets

- Quality Editorial service

- Swift Peer Review

- Reprints availability

- E-prints Service

- Manuscript Podcast for convenient understanding

- Global attainment for your research

- Manuscript accessibility in different formats

( Pdf, E-pub, Full Text, Audio)

- Unceasing customer service

Track the below URL for one-step submission https://juniperpublishers.com/online-submission.php 